\title{
KNOWLEDGE OR INFORMATION: EXPLORING THE LIMITATIONS OF FUNCTIONAL LITERACY IN THE INDIAN SUBCONTINENT
}

\author{
Devika Goyal \\ The Shri Ram School, Moulsari \\ DOI: 10.46609/IJSSER.2020.v05i03.020 URL: https://doi.org/10.46609/IJSSER.2020.v05i03.020
}

\begin{abstract}
Functional literacy programs have gained traction throughout the developing world, including India. These programs have focused on enabling illiterate people with the basic skills required to contribute productively to society and improve their socio-economic status. Over time, the definition and conception of functional literacy has become wider to encompass more dimensions and disciplines. While the government of India has implemented several functional literacy programmes, there still exists mass illiteracy, including a significant gender gap. This paper will critically examine the limitations of the existing programs and examine the best practices that exist in other developing nations. It will also focus on the changing definitions of functional literacy. The paper will then pose policy recommendations for aspects that can be incorporated into functional literacy programs to better address existing limitations, and what India can learn from other countries and international recommendations.
\end{abstract}

Keywords: Functional literacy, Education, Social change, Social awareness, Learning

\section{INTRODUCTION}

Several developing countries including India, have increased their focus on functional literacy over the past couple of decades. Functional literacy was officially defined as a term by UNESCO in 1960, as:

'the set of tangible skills: reading and writing, which in the context of a globalizing world, means from a simple process of acquiring basic cognitive skills to 'using these skills in ways that contribute to socio-economic development, to developing the capacity for social awareness and critical reflection as a basis for personal and social change", (IGI Global; UNESCO, 2004). 


\section{International Journal of Social Science and Economic Research}

ISSN: $2455-8834$

Volume: 05, Issue: 03 "March 2020"

Therefore, it can be construed as the ability to read and write on a basic level, and perform basic mathematical calculations (IGI Global; UNESCO, 2004). In most developing countries including India, this has led to programs for the poor and marginalized to be able to attain these basic skills. Perhaps the biggest example of programs to promote functional literacy in India is the National Literacy Mission, which was started in 1988. It encompasses four programmes Sakshar Bharat, Sarva Shiksha Abhiyan, Rashtriya Madhyamik Shiksha and teacher training programs (Basu, 2004).

The National Literacy Mission defines literacy as acquiring the skills of reading, writing and arithmetic and the ability to apply them to one's day-to-day life (Basu, 2004; MHRD, 2008). The achievement of functional literacy implies (i) self-reliance in 3 R's, (ii) awareness of the causes of deprivation and the ability to move towards amelioration of their condition by participating in the process of development, (iii) acquiring skills to improve economic status and general well being, and (iv) imbibing values such as national integration, conservation of environment, women's equality, observance of small family norms (Basu, 2004; MHRD, 2008).

There have been several other efforts targeted at women, farmers, and rural areas as well. Over time, the implementation of these programs has become more widespread (MHRD, 2008). This essay will critically examine the roles of functional literacy and contrast it with other forms of literacy. It will critique the implementation of functional literacy based programs and examine the forms in which it could be more holistic. Finally, the paper will pose recommendations to update such programs for the technological age.

\section{BACKGROUND}

The definition of functional literacy, as arrived at by the National Literacy Mission and UNESCO, has evolved over time from something purely based on utility to a more critical approach (UNESCO, 2004). It has moved from basic skills to an appreciation of social issues, and reflecting on how to improve one's economic status. The National Literacy Mission has also, over time, sought to put more of a focus on gender disparities and the literacy of women (MHRD, 2008). Development literacy is as important as functional literacy, because it is key for people to be able to continue to progress in skills to effectively communicate, rather than a static conception of literacy. Literacy development refers to the on-going development of skills needed to successfully communicate through written communication (Pate and Grote-Garcia, 2011). There does seem to be a focus on on-going skill development in government programs.

Between 1949 and 1966, the concept used was 'civic literacy' which was based on a life-oriented approach and focused on social education. Between 1967 and 1977, 'functional literacy' concept based on a work-oriented approach came to be emphasized in adult education which focused on 


\section{International Journal of Social Science and Economic Research}

ISSN: $2455-8834$

Volume: 05, Issue: 03 "March 2020"

functional literacy programme, farmer's education and Shramik Vidyapiths. From 1978 onwards, 'developmental literacy' concept based on social change approach came to be used more which focused on total literacy campaigns (Smrutiksha, Your Article Library).

However, the literacy rate in India does continue to be worrisome. Apart from imparting basic literacy and numeracy skills, the NLM also sparked off discussions and dialogue on relevant social issues such as women empowerment, domestic abuse and alcoholism. However, towards the end of the mission, the voluntary nature of the mission got diluted, and the mission lost efficacy (Chandra, 2019). A brief analysis of existing policies and schemes implemented by the Government of India reveal that policies such as Sakshaar Bharat (2009) were unable to completely meet the objectives set due to motivational lapses amongst the beneficiaries. Due to problems such as legal identification and form-filling procedures, the number of citizens benefiting from these programs was severely limited, especially in rural areas. This directly identifies the need for functional literacy and highlights how existing and new schemes would be more successful if functional literacy was the base for them. Moreover, schemes launched at the national level may serve basic purposes but miscoordination at the grass roots level and lack of community specific implementation along with the programs nt being tailored to serve the diverse communities has led to policy inadequacies. It is therefore crucial to mobilise volunteers and seek community participation for the success of any adult literacy campaign. As mentioned in the draft of the National Education Policy 2019, if every literate member of the community could commit to teaching one student/person how to read, it would change the country's landscape very quickly (Chandra, 2019).

In developing economies particularly, there is a need to tailor functional literacy programs to address the socio cultural and economic context. Especially among the poor and rural population, one of the biggest dispositional barriers preventing older adults from engaging in literacy programmes is that they see little utility and relevance for the same (Blunch, 2017). However, if such programmes are linked to learning additional skills such as vocational training, then they are likely to solicit wider participation (Blunch, 2017). Therefore, in order to provide incentives for adult literacy programmes, it must be designed to place literacy learning in the context of rights awareness, health and food security (such as in Zambia), reproductive health, community mobilisation and communication (Gambia), and learning skills that support income-generating activities (Sierra Leone; Blunch, 2017). In order to close the literacy gender gap for older adults, adult literacy programmes that also offer women training in skills such as bangle-making, blockpainting, jute-work and other handcrafts should be designed to elicit greater participation. Such localized projects are of great use. Linking literacy programs to employment schemes has also proven to be useful in getting adults to avail of the programs (Blunch, 2017). 


\section{International Journal of Social Science and Economic Research}

ISSN: $2455-8834$

Volume: 05, Issue: 03 "March 2020"

There has been progress in relation to child and youth literacy in India, although significant barriers especially in the education of young girls remains. Child and youth literacy numbers for both males and females show that sustained efforts to improve literacy have borne fruit over the years (Smrutiksha, Your Article Library). The introduction of the Mid-Day-Meal Scheme (1995), for example, and the Sarva Shiksha Abhiyan (2001), as well as the enactment of RTE (Right to Education Act, 2009) have contributed significantly to improving literacy. According to the latest available data, child and youth literacy in India stands at 93 percent and 94 percent, respectively (Chandra, 2019).

It is documented that functional literacy programs improve the socio economic status of those it is targeted towards. However, there is a gap in the research regarding the cause and effect relationship of these programs. A large part of this knowledge gap is due to a lack of relevant data (Chandra, 2019). Often, researchers must rely on already a vailable data from, for example, the World Bank's Living Standards Measurements Surveys, which are prone to potential issues of self-selection and non-random program placement (Chandra, 2019; Blunch, 2017). Recent research has certainly attempted to establish cause-effect relationships through applications of a combination of instrumental variables and community fixed effects, though much more research is called for in the future to try to better understand what works, and why (Blunch, 2017). Therefore, better secondary research needs to be conducted to understand causal relations to develop more effective implementation methods.

\section{DISCUSSION}

A key point of discussion for the future of functional literacy programs is the question of where to draw the line between 'functional' and 'essential'. Functional literacy programs often focus on basic written communication and mathematical calculations, as well as basic vocational skills. However, there are not many documented programs where arts and humanities are put into focus, and if so, are only found in programs of urban areas and more affluent schools. Recently in 2018, the Vice President of India made a statement that the country must move on from universal functional literacy to skill development and lifelong learning (India Today, 2018). Therefore, there is a suggestion that there are consequences to prioritizing only functional literacy, and it could create an atmosphere of moving away from holistic education as the opportunity cost of focusing only on career-based skills. Therefore, it is key to analyze functional literacy from multiple socio-political and cultural contexts in the country.

From a cultural relativist perspective, one notes the multiple and diverse connotations attached to the phrase "functional" both across countries as well with intra-national differences in social, economic, and regional contexts that shape the constructs of utility and functionality in 


\section{International Journal of Social Science and Economic Research}

ISSN: $2455-8834$

Volume: 05, Issue: 03 "March 2020"

professional environments. In India, for instance, the linguistic diversity and postcolonial history itself necessitates an understanding of the English language as a crucial tool for professional capacity in order to possess upwards mobility and break class barriers and obtain access to social centers of influence. On the other hand, in many other countries in the world, knowledge of the English language in itself would not suffice as an adequate or useful functional literacy skill. In those cases, functional literacy could entail regional language education, or perhaps more culturally suited forms -- block-printing in rural areas, to encourage social entrepreneurship at the most basic levels, handloom weaving, cooking, each of these could facilitate functional literacy at multiple levels, in some cases more so than existing standardized curriculums.

This therefore stands to be the primary critique of existing universalized and generalized modes of functional literacy education -- it calls in question the need to reconcile cultural variances in social and economic factors with resource limitations and the requirement to enforce a standardized policy with limited manpower for skilling endeavors. It calls to question a discussion rooted in the Global South on what "functional" truly means. It further brings to focus the need to incorporate grassroots-level insights to create functional literacy programs and training curriculums that are truly effective, truly cultural, and specifically suited to the hyperlocal needs of regions.

Older definitions and programs centered around functional literacy focused on productivity as the main outcome. In 1973, UNESCO described it as:

'an activity aimed at the intellectual and civic training of the worker and his adaptation to the industrial environment and its technical demands. By extending the benefits of functional literacy to the greatest possible number of illiterate workers, greater overall productivity is obtained from the individual firm; and this-be it remembered-is one of the necessary conditions for national development' (Bellahsene, 1973).

However, as previously mentioned, this definition has now changed to a concept that is broader, more holistic and inclusive of alternative perspectives. However, there continues to be a need for functional literacy, as a threshold requirement prior to the exploration of these larger realms of artistic knowledge. The policies and decisions made under the purview of such a holistic mindset must therefore be evaluated in their application and target audience.

Literacy programs in the past have been formulated with the intention of providing neo-literate citizens opportunities to improve their financial conditions and facilitate development in local communities. In the case of rehabilitation of adults and providing occupational mobility, it is important to compare the importance of functional literacy and artistic knowledge. While holistic 


\section{International Journal of Social Science and Economic Research}

ISSN: $2455-8834$

Volume: 05, Issue: 03 "March 2020"

development from a primary level may help in eradicating the problem of illiteracy, for back to work adults it seems that functional literacy may be more essential in earning a livelihood. Factors of time and viability also affect the impartment of artistic knowledge.

Often functional literacy programs require a shorter time period and seem to be more viable for adults. In terms of the urban poor in cities of the Third World, benefits endowed by functional literacy programs may be valued more than those endowed by programs focusing on holistic growth. This would lead to formulation of more successful policies with higher motivation amongst the targeted citizens. This is not to undermine the importance and growing realisation for the need of holistic curriculums. Holistic development from a primary level may help in eradicating the problem of illiteracy by enabling students to realise their potential. Artistic knowledge in the long run may allow a citizen to acquire life skills and appreciation of cultural and community norms, making them socially contributing citizens. Programs that implement changes in curriculums at a primary level allowing literacy to go beyond the rudimentary level is an aspect that is being focused on by policy makers and educators around the world.

A key dimension to also consider other than incorporating the arts and humanities into functional literacy programs is to also include minorities (UNDP India, 2017). Leadership training programmes supported by UNDP have helped trans women and men seize opportunities that weren't available before (UNDP India, 2017). Inculcating respect for personhood and awareness on sexual health and family planning is also key for rapidly growing economies such as India to achieve holistic literacy (UNDP India, 2017). Further, it is important that there be more programs focused towards the holistic education of women, given the gender gap in functional literacy in India (Chandra, 2019). This is due to a combination of an existing gender gap with respect to primary and early secondary education with the gender gap for functional literacy -the existing barriers to access, therefore, are complex entities stemming from basic limitations such as difficulties with filing forms for applying to such schemes, and further with regards to official documentation, social stigma with respect to working women especially in communities from lower class and caste backgrounds, and a plethora of other regions ranging from religious to caste discrimination in intersection with patriarchal gender norms.

Furthermore, programs for health literacy, sex education and education on contraception is extremely important in the context of the Third World, including countries such as India. This needs to be implemented at a school level to educate adolescents and also incorporate it into adult literacy programs to improve family planning, and reduce the incidence of sexually transmitted diseases, HIV/AIDS, and generally increase awareness on important issues and break cultural barriers (WHO, 2010). 


\section{International Journal of Social Science and Economic Research}

ISSN: $2455-8834$

Volume: 05, Issue: 03 "March 2020"

\section{CONCLUSION}

There are several success stories of successful functional literary programs that have achieved success and shows that it can lift citizens out of poverty and allow them to exercise their rights to improve their socio economic conditions. For example, since 2009, the UNDP in partnership with NABARD and the Indian School of Microfinance for Women has equipped thousands of women with financial literacy skills critical to meeting the objectives of financial inclusion in India (UNDP India, 2012). Less than 60 percent of the adult population in rural areas has access to basic banking services. Much of the success of efforts to deepen financial inclusion will depend on the effectiveness of business correspondents to take the message of financial inclusion to far flung areas (UNDP India, 2012). UNDP with NABARD has strengthened the technical capacities of business correspondents in four states - Jharkhand, Madhya Pradesh, Rajasthan and Uttar Pradesh (UNDP India, 2012).

Countries in the Global South have particular needs, which need to be addressed depending on the cultural context. However, policy recommendations and government focus has mainly been around adult literacy programs, which seek to tackle the already illiterate adults who then will in turn educate their children (Blunch, 2017). By inculcating knowledge regarding health, education and societal living, a virtuous cycle of development can be established. Focusing on adult literacy programs is a good step, however, they should not be seen as an alternative to the formal education system. Rather, they can be seen as a complement to the formal education system, by offering adults who never went to school as children (or, if so, only very briefly) an alternative way of improving their human capital and obtaining more general life skills (Blunch, 2017). Functional literacy beyond a threshold may even serve as a base for acquiring a more dynamic frame of knowledge and skillset.

Incorporating technology into literacy programs is the watchword for developing countries. For example, in Eritrea in Africa, radio programmes are broadcast in four local languages to support literacy, post-literacy, agricultural and health programmes (Chandra, 2019). In Niger, the use of mobile phones combined with adult literacy programs improved their learning outcomes (Chandra, 2019). An example of such an initiative is the Computer-Based Functional Literacy (CBFL) solution, which is empowering tens of thousands of people in India and other countries (Brodie, 2017). The lack of trained teachers and inadequate infrastructure present substantial barriers to improving adult literacy. CBFL is a user-friendly solution that an instructor can easily operate, even without prior computer training (Brodie, 2017). In India, this has reached places such as women in traditional communities and villages, as well as prisons (Brodie, 2017). Such innovative solutions and teaching adults and youth to harness the power of technology and social 


\section{International Journal of Social Science and Economic Research}

ISSN: $2455-8834$

Volume: 05, Issue: 03 "March 2020"

media will go a long way to update their level of literacy for the digital age. What is important is the development of long term programs which do not get discontinued too soon (Chandra, 2019).

As India develops into a $21^{\text {st }}$-century knowledge economy, the definition of literacy must therefore effectively evolve to reflect the changing needs of society; this can only occur, ultimately, through participatory modes of policymaking and development that are open to changes on the basis of existing structural and social limitations towards both the access to and the effective utilization of skilling endeavors and functional literacy programmes. Literacy should not be confined to the basic, foundational skills of reading and writing but linked to the broader notions of financial, digital, civic and multicultural literacy (Chandra, 2019). For truly sustainable and implementable policy solutions to emerge, there must be continued discussion and debate on its meaning, and its various dimensions.

\section{REFERENCES}

Basu, K., (November 2004). "Educating India', Scribd

Bellahsène, C, (1973), 'Practical guide to functional literacy: a method of training for development', UNESCO Experimental World Literacy Program

Blunch, N, (2017), 'Adult literacy programs in developing countries'. IZA World of Labor, Volume 374

Brodie, C., (September 2017), 'This technology is boosting literacy rates in India and beyond', Digital Empowers

Chandra, T., (October 2019), "Literacy in India: The Gender and Age Dimension", ORF Issue Brief No. 322, Observer Research Foundation.

IGI Global, 'What is Functional Literacy', available at https://www.igiglobal.com/dictionary/literacy-integral-definition/36316

India Today Web Desk, (July 31 2018), 'Our country must move on from functional literacy to lifelong learning: Venkaiah Naidu’, India Today

Ministry of Human Resource Development, (September 2008), Efforts to Eradicate Illiteracy in India

Pate R.S., Grote-Garcia S.A. (2011) Literacy Development. In: Goldstein S., Naglieri J.A. (eds) Encyclopedia of Child Behavior and Development. Springer 
International Journal of Social Science and Economic Research

ISSN: $2455-8834$

Volume: 05, Issue: 03 "March 2020"

Smrutishikha, Adult Education Programme for Literacy in India', Your Article Library,

UNDP India, (December 1 2017), 'New Skills, New Lives'

UNDP India, (2012), 'Functional Literacy - The Language of Empowerment'

UNESCO Education Sector, (2004), "The Plurality of Literacy and its implications for Policies and Programmes: Position Paper

World Health Organization, (2010), 'Developing Sexual Health Programs: A Framework for Action', Department of Reproductive Health and Research. 